\title{
Frequency of EGFR Mutation and EML4-ALK fusion gene in Arab Patients with Adenocarcinoma of the Lung
}

\author{
Hanan Ezzat Shafik ${ }^{1 *}$, Mohamed Ashour² \\ ${ }^{1}$ Department of Medical oncology, \\ National Cancer Institute,Cairo, Egypt
}

${ }^{2}$ Department of Clinical Oncology,

Al Azhar University, Cairo, Egypt

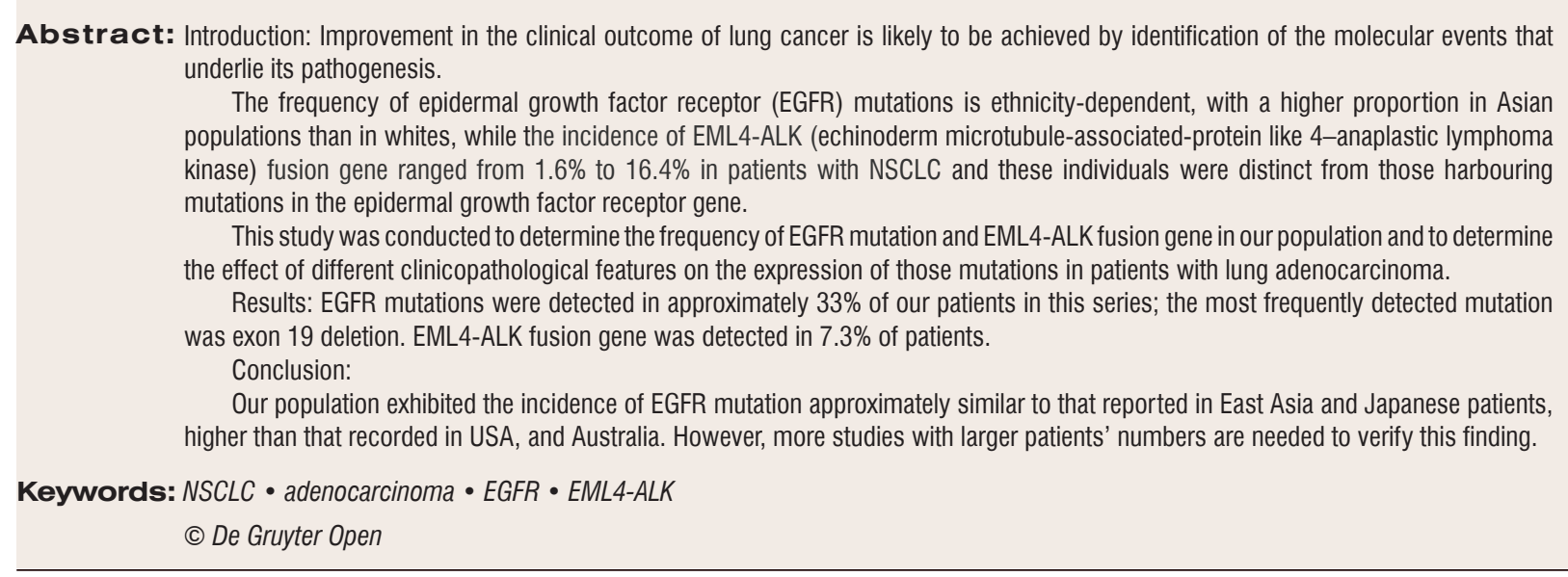

\section{Introduction}

Although lung cancer remains the leading cause of cancer-related mortality for both men and women worldwide accounting alone for a quarter of all cancer deaths. Recent years have seen advances in the understanding and treatment of this difficult malignancy. Knowledge about molecular subsets of lung cancer defined specific oncogenic aberrations like epidermal growth factor receptor (EGFR), Kirsten Rat Sarcoma viral oncogene (KRAS) and anaplastic lymphoma kinase (ALK) that control the proliferation of cancer cells. This renders some cancers sensitive to therapeutic inhibitors targeting the mutated pathway for example; gefitinib, erlotinib and afatinib targeting EGFR-mutated NSCLC and crizotinib targeting ALK-rearranged NSCLC. [1, 2]

EGFR is a member of the Erb-B family of transmembrane receptor tyrosine kinases involved in signal transduction pathways that regulate proliferation and apoptosis. Activating EGFR mutations such as exon 19 deletions and exon 21 (L858R) substitutions are pertinent to NSCLC [3]. Lung cancers harbouring EGFR mutations have a high sensitivity to EGFR-tyrosine kinase inhibitors (TKI) because these tumours are dependent on the EGFR signalling pathway for their survival and proliferation [4].

Certain groups of patients with NSCLC, such as those with adenocarcinoma histology, women, Asian ethnicity and nonsmokers are reported to be more likely to have tumour responses to EGFR-TKIs than other groups [5].

Data from 13 phase III trials in which an EGFR-TKI were compared with platinum-based chemotherapy were summarized in a meta-analysis that included data of 2620 patients (1475 EGFR mutation positive and 1145 mutation negative). Time to progression was significantly prolonged in EGFR-TKI group (hazard ratio (HR) 0.43 , 
95\% Cl 0.38-0.49), while no effect on OS was observed (HR 1.01, 95\% Cl 0.87-1.18) [6].

ALK mutations have been identified in several types of cancer, including anaplastic large-cell lymphoma, neuroblastoma, inflammatory myofibroblastic tumour and NSCLC. [7] In NSCLC, the potential driver mutation is a fusion of an intrachromosomal inversion on the short arm of chromosome 2 that joins exons 1-13 of the Echinoderm microtubule-associated-protein like 4 gene (EML4) to exons 21-29 of ALK $[7,8]$. The resulting EML4-ALK is a fusion of the N-terminal portion of the protein encoded by EML4, with the intracellular signalling portion of the receptor tyrosine kinase encoded by the ALK gene [7, 9, 10].

EML4-ALK is uncommon, occurring in $2 \%$ to $7 \%$ of all NSCLC, and is more prevalent in patients who have never smoked or who have a history of light smoking and in patients with adenocarcinomas. [11] EGFR, ALK are mutually exclusive in patients with NSCLC, and the presence of one mutation in lieu of another can influence response to targeted therapy. Therefore, testing for these mutations and tailoring therapy accordingly is widely accepted as standard practice.

The tests of genes mutation (EGFR, ALK and ROS1) were adapted in many countries to determine the appropriate treatment. However, the reported incidences of gene mutations among adenocarcinoma lung patients in our populations are still lacking.

The aim of our study is to report the frequency and pattern of EGFR mutations as well as ALK gene rearrangement in patients attending Medical Oncology out-patient clinic, Kuwait Cancer Control Center (KCCC) with lung adenocarcinoma.

\section{Patient and methods}

According to KCCC policy specimens from 110 cases diagnosed with adenocarcinoma of lung origin between June 2010 till June 2014 were sent to lab 21 London for EGFR testing, samples which were found negative to EGFR were subjected to ALK testing. The median time required for such analysis was 10 days (range: 7-14) from the time the sample arrived at the laboratory until the results were reported.

Genomic DNA was isolated from formalin-fixed paraffin-embedded tumour tissues. Genetic analysis of the EGFR gene was performed using Therascreen EGFR PCR kit. Twenty-eight different mutations in EGFR gene were studied with three targets being mutation specific (L858R, L861Q, S7681). The other 25 targets were detected if present but were grouped into 3 types (deletion 19, G719x and insertion 20). ALK FISH gene rearrangement testing was performed using the CE-marked Vysis LSI ALK Break Apart Rearrangement Probe Kit. Interpretation of the results was based on the review by Lindeman et al. [13]

Data of the patients was then retrospectively analysed.

\section{Results}

Specimens from 110 patients with NSCLC (adenocarcinoma) received at KCCC out-patient clinic between June 2010 and June 2014 were collected and sent to laboratory 21, London, UK, for EGFR and ALK testing. Mean age of the patients was $61.37 \pm 10.45$. Males represented $63.3 \%$ from the patients and females $36.4 \%$. Forty-one patients (37.3\%) were smokers. All patients were of Arab ethnicity out of which 57 (51.8\%) were Kuwaitis. Demographic characteristics of the patients are shown in table 1.

Thirty-six patients $(32.7 \%)$ carried EGFR mutation. The most frequently detected mutation was exon 19 deletion in 18 patients (50\%), followed by exon 21 (L858R) substitution in 14 patients (39\%) then G719X mutation and Insertion 29 in two patients (5.5\%) each.

Table 1: Demographic characteristics of all patients.

\begin{tabular}{|c|c|c|}
\hline \multirow{2}{*}{$\begin{array}{l}\text { Patients } \\
\text { characteristics }\end{array}$} & \multicolumn{2}{|c|}{ Patients number, $\mathbf{N}=110$} \\
\hline & $\mathbf{n}$ & (\%) \\
\hline $\begin{array}{l}\text { Mean age } \\
\text { Age group }\end{array}$ & \multicolumn{2}{|c|}{$61.37 \pm 10.45$} \\
\hline$\leq 60$ & 51 & $(46.4)$ \\
\hline$>60$ & 56 & (53.6) \\
\hline \multicolumn{3}{|l|}{ Sex } \\
\hline Male & 70 & (63.6) \\
\hline Female & 40 & $(36.4)$ \\
\hline \multicolumn{3}{|l|}{ Smoking } \\
\hline Smoker & 41 & (37.3) \\
\hline Nonsmoker & 69 & (62.7) \\
\hline \multicolumn{3}{|l|}{ Nationality } \\
\hline Kuwaiti & 57 & $(51.8)$ \\
\hline Non-Kuwaiti & 53 & $(48.2)$ \\
\hline Histology & \multicolumn{2}{|c|}{ Adenocarcinoma } \\
\hline Stage at diagnosis & \multicolumn{2}{|c|}{ IV } \\
\hline
\end{tabular}


Table 2: Frequency of EGFR mutation types.

\begin{tabular}{l|cc}
\hline Mutation type & \multicolumn{2}{|c}{$\mathbf{N = 1 1 0}$} \\
& $\mathbf{n}$ & (\%) \\
\hline \hline EGFR negative & 74 & $(67.3)$ \\
EGFR positive & 36 & $(32.7)$ \\
Exon 19 deletion & 18 & $(16.4)$ \\
Exon 21 (L858R) substitution & 14 & $(12.7)$ \\
G719X mutation & 2 & $(1.8)$ \\
Insertion 29 & 2 & $(1.8)$ \\
ALK gene mutation & 8 & \\
\hline
\end{tabular}

Table 3: Patient's characteristics by EGFR status.

\begin{tabular}{|c|c|c|c|c|c|}
\hline \multirow[t]{2}{*}{ Characteristic } & \multicolumn{2}{|c|}{$\begin{array}{c}\text { EGFR } \\
\text { Mutated, } \\
\mathbf{N}=36\end{array}$} & \multicolumn{2}{|c|}{$\begin{array}{c}\text { EGFR Wild, } \\
\qquad \begin{array}{c}\mathrm{N}=74\end{array}\end{array}$} & \multirow[t]{2}{*}{$\begin{array}{c}\mathbf{P} \\
\text { Value }\end{array}$} \\
\hline & & (\%) & & (\%) & \\
\hline $\begin{array}{l}\text { Mean age at } \\
\text { diagnosis }\end{array}$ & \multicolumn{2}{|c|}{$61.6 \pm 9.9$} & \multicolumn{2}{|c|}{$61.3 \pm 10.8$} & 0.18 \\
\hline Age & & & & & 0.186 \\
\hline$\leq 60$ & 14 & (38.9) & 37 & (50) & \\
\hline$>60$ & 22 & $(61.1)$ & 37 & (50) & \\
\hline Sex & & & & & 0.004 \\
\hline Male & 16 & $(44.4)$ & 54 & (73) & \\
\hline Female & 20 & $(55.6)$ & 20 & (27) & \\
\hline Smoking & & & & & 0.06 \\
\hline Nonsmoker & 27 & (75) & 42 & $(56.8)$ & \\
\hline smoker & 9 & (25) & 32 & $(43.2)$ & \\
\hline Nationality & & & & & 0.5 \\
\hline Kuwaiti & 17 & $(47.2)$ & 40 & (54) & \\
\hline Non-Kuwaiti & 19 & $(52.8)$ & 34 & (46) & \\
\hline
\end{tabular}

ALK gene rearrangement was detected in eight patients $(7.3 \%)$, table 2 .

Incidence of EGFR mutation was found to be higher in females. Out of the 36 patients harbouring EGFR mutations, females represented $55.6 \%$ and males represented $44.4 \%$ while in EGFR wild population females represented $27 \%$ and males represented $73 \%$, a difference which was statistically significant, $P=0.004$.

The frequency of EGFR mutation was found to be higher in never smokers than smokers. In our patients series the frequency was $(75 \%$ versus $25 \% ; p=0.06)$ a difference which is nearly significant.
Table 4: Patient's characteristics by ALK status.

\begin{tabular}{|c|c|c|c|c|c|}
\hline \multirow{2}{*}{$\begin{array}{l}\text { Patient's } \\
\text { characteristic } \\
\begin{array}{l}\text { Mean age at } \\
\text { diagnosis }\end{array}\end{array}$} & \multicolumn{2}{|c|}{$\begin{array}{c}\text { ALK } \\
\text { negative, } \\
\mathrm{N}=102 \\
\mathrm{n}(\%)\end{array}$} & \multicolumn{2}{|c|}{$\begin{array}{c}\text { ALK positive, } \\
\begin{array}{c}\mathbf{N}=\mathbf{8} \\
\mathrm{n}(\%)\end{array}\end{array}$} & \multirow{2}{*}{$\begin{array}{c}\begin{array}{c}\mathbf{P} \\
\text { Value, }\end{array} \\
\\
0.006\end{array}$} \\
\hline & & 10.1 & & \pm 10.1 & \\
\hline Age & & & & & 0.015 \\
\hline$\leq 60$ & 44 & $(43.1)$ & 7 & $(87.5)$ & \\
\hline$>60$ & 58 & (56.9) & 1 & (12.5) & \\
\hline Sex & & & & & 0.4 \\
\hline Male & 66 & $(64.7)$ & 4 & (50) & \\
\hline Female & 36 & (35.5) & 4 & (50) & \\
\hline Smoking & & & & & 0.46 \\
\hline Nonsmoker & 63 & (61.8) & 6 & (75) & \\
\hline Smoker & 39 & (38.2) & 2 & (25) & \\
\hline Nationality & & & & & 0.53 \\
\hline Kuwaiti & 52 & (51) & 5 & (62.5) & \\
\hline Non-Kuwaiti & 50 & (49) & 3 & (37.5) & \\
\hline
\end{tabular}

The mean age did not differ between EGFR positive and negative patients $(p=0.18)$, and there was no difference in the incidence of EGFR mutations in Kuwaitis and patients from other Arab countries, table 3 .

Younger patients exhibited a higher incidence of ALK mutation $(87.5 \%$ versus $12.5 \% p=0.015)$ in patients $\leq 60$, and those $>60$, respectively. There was no difference in the incidence of ALK mutation between males and females, smokers and nonsmokers and finally Kuwaitis and non-Kuwaitis, table 4.

\section{Discussion}

In our study we examined 110 patients with adenocarcinoma for gene mutations, in which 36 $(32.7 \%)$ patients exhibited EGFR mutations and 8 (7.3\%) exhibited ALK gene rearrangement. The observed EGFR mutations frequency in our study were approximately similar to that reported in East Asia and Japanese patients, higher than the recorded in USA, Australia and India. Vietnam, Taiwan and Thailand showed the highest incidence. The reported EGFR mutation frequency in Arab region was from Moroccan patients. They reported a $21 \%$ incidence which is still lower than ours $[13,14]$, table 5. 
Table 5: Molecular epidemiology status of EGFR mutation [16]

\begin{tabular}{l|cc}
\hline Region & Incidence & Mutation rate \\
\hline \hline Vietnam & $77 / 120$ & $64.2 \%$ \\
Japan & $71 / 263$ & $27 \%$ \\
East Asia & $107 / 361$ & $30 \%$ \\
Taiwan & $108 / 174$ & $62.1 \%$ \\
Thailand & $63 / 117$ & $53.8 \%$ \\
Philippines & $34 / 65$ & $52.3 \%$ \\
China & $372 / 741$ & $50.2 \%$ \\
Hong Kong & $76 / 161$ & $47.2 \%$ \\
United States of America & $11 / 80$ & $14 \%$ \\
Australia & $6 / 83$ & $7 \%$ \\
India Chennal & $16 / 72$ & $22.2 \%$ \\
India (Tata Memorial Hospital) & $202 / 780$ & $26 \%$ \\
\hline
\end{tabular}

Among subtypes of EGFR mutation exon 19 Del was detected in 50\%, exon 21 (L858R) substitutions in 39\%, D719x mutation and insertion in 5.5\%. Our results are consistent with those reported by Sharma et al. where exon 19 Del was detected in $45 \%$ of patients, exon 21 (L858R) substitution in $40-45 \%$ of patients and D719x in $5 \%$ of patients. [15] Similar incidence was observed by Anuradha et al., 50\% deletions in exon 19, 42\% exon 21 (L858R) substitution and 7\% of the mutation in exon 18. [14] The same was reported in IPASS trial. [18] Hassan et al. reported EGFR mutations to be mainly detected in exon $19(69 \%)$ followed by exon $21(21 \%)$ and exon 20 $(7 \%)$, whereas mutations in the exon 18 were rare $(3 \%)$ that slightly differ than what is seen in the current study. [14] Another report released by Ismaili et al. in Moroccan population showed the overall frequency of the EGFR mutation to be $21 \%$. Mutations were mainly detected in exon 19 (69\%), followed by Exon 21 (21\%) and exon 20 $(7 \%)$, whereas mutations in the exon 18 were rare $(3 \%)$. This percentage is slightly higher than our study but with the same pattern of distribution among different type of mutation [16].

In our study incidence of EGFR mutations were higher in females than males $(55.6 \%, 44.4 \%)$ respectively. Females represented only $27 \%$ of EGFR wild population and males represented $73 \%$, a difference which was statistically significant, $P=0.004$. A finding which was recorded in different studies [17, 14].
In this study there was no significance difference in mean age between EGFR mutated and nonmutated patients $(p=0.18)$. Similar results were reported by other studies. [18]In this study no difference in incidence of EGFR mutations in Kuwaitis and patients from other Arab countries.

It has been reported that exon 18 EGFR mutations are detected more frequently in younger patients, which was also noted in our study [19].

In a review by Shigematsu and Gazdar, $45 \%$ of never smokers had EGFR mutations, whereas only $7 \%$ of smokers had EGFR mutations [20]. The high frequency of EGFR mutations in never smokers is consistent across different ethnic and geographic groups. Similar result was detected in this study. The frequency of EGFR mutation in never smokers was significantly higher than smoker patients $(75 \%$ versus $25 \% ; p=0.06$ ). Furthermore, it has been reported that the frequency of EGFR mutations is inversely associated with the amount of exposure to tobacco smoke, for both passive and active smoking [21].

The overall frequency of ALK fusion oncogene in the general NSCLC population is low 2 to $7 \%$. (4 introduction). The frequency in our study was $7.3 \%$. Similar frequencies have been reported in Asian and Western populations [22]. One study showed a 13\% incidence in metastatic NSCLC in Western populations and a $22 \%$ in never/light smokers and among never or light smokers who did not have an EGFR mutation, the frequency was $33 \%$. Also, ALK fusion oncogene-positive lung cancer is observed in younger and adenocarcinoma patients. [8] Data which are consistent with ours where ALK gene rearrangement was higher in younger patients ( $87.5 \%$ versus $12.5 \% p=0.015$ ), in patients $\leq 60$ and those $>60$, respectively. There was no difference in incidence of ALK mutation between males and females, smokers and nonsmokers and finally Kuwaitis and nonKuwaitis.

\section{Conclusion}

Our population exhibited incidence of EGFR mutation approximately similar to that reported in East Asia and Japanese patients, higher than that recorded in USA, and Australia. Incidence of ALK gene rearrangement is approximately similar to that reported by other trials. However, more studies with larger patient's numbers are needed to verify these finding. 
[1] Siegel R, Naishadham D, Jemal A. Cancer statistics, 2013. CA Cancer J Clin. 2013;63:11-30.

[2] Stella GM, Scabini R, Inghilleri $S$, et al. EGFR and KRAS mutational profiling in fresh non-small cell lung cancer (NSCLC) cells. J Cancer Res Clin Oncol. May 52013.

[3] Yasuda H, Park E, Yun CH, et al: Structural, Biochemical, and Clinical Characterization of Epidermal Growth Factor Receptor (EGFR) Exon 20 Insertion Mutations in Lung Cancer. Sci Transl Med. 2013;5: 216 ra177.

[4] Goodin S. Erlotinib: Optimizing therapy with predictors of response? Clin Cancer Res 2006;12:2961-2963.

[5] Ji H, Li D, Chen L, Shimamura T, et al. The impact of human EGFR kinase domain mutations on lung tumorigenesis and in vivo sensitivity to EGFRtargeted therapies. Cancer Cell 2006;9:485-95.

[6] Lee, C.K., Brown, C., Gralla, R.J., et al. (2013) Impact of EGFR Inhibitor in Non-Small Cell Lung Cancer on Progression-Free and Overall Survival: A Meta-Analysis. Journal of the National Cancer Institute, 105, 595-605. http://dx.doi.org/10.1093/ jnci/djt072.

[7] Lee, C.K., Brown, C., Gralla, R.J., et al. (2013) Impact of EGFR Inhibitor in Non-Small Cell Lung Cancer on Progression-Free and Overall Survival: A Meta-Analysis. Journal of the National Cancer Institute, 105, 595-605. http://dx.doi.org/10.1093/ jnci/djt072

[8] Soda M, Choi YL, Enomoto M, et al. Identification of the transforming EML4ALK fusion gene in nonsmall-cell lung cancer. Nature 2007; 448:561-6.

[9] Ou SH. Crizotinib: a novel and first-in-class multitargeted tyrosine kinase inhibitor for the treatment of anaplastic lymphoma kinase rearranged non-small cell lung cancer and beyond. Drug Des Devel Ther. 2001;5:471-85.

[10] Rikova K, Guo A, Zeng Q, et al. Global survey of phosphotyrosine signaling identifies oncogenic kinases in lung cancer. Cell. 2007;131:1190-1203.

[11] Thunnissen E, Bubendorf L, Manfred D, et al. EML4-ALK testing in non-small cell carcinomas of the lung: a review with recommendations. Virchows Arch. 2012;461:245-57.

[12] Wong DW, Leung EL, So KK, et al. The EML4-ALK fusion gene is involved in various histologic types of lung cancers from nonsmokers with wild-type EGFR and KRAS. Cancer 2009;115:1723-33.
[13] Lindeman NI, Cagle PT, Beasley MB, et al. Molecular Testing Guideline for Selection of Lung Cancer Patients for EGFR and ALK Tyrosine Kinase Inhibitors. Journal of Thoracic Oncology. 2013; 8(7):823-859.

[14] Anuradha Ch, Kumar P, Vanita N, et al. Frequency of EGFR Mutations in 907 Lung Adenocarcioma Patients of Indian Ethnicity. PLOS ONE, October 2013;8(10):e76164 www.plosone.org.

[15] Hassan E, Hanane In, Anouar B, et al. Frequency and Type of Epidermal Growth Factor Receptor Mutations in Moroccan Patients with Lung Adenocarcinoma. Journal of Thoracic Oncology, September 2013;8:9.

[16] Sharma S, Bell D, Settleman J, and Haber D. Epidermal Growth Factor Mutation in Lung Cancer. Nature Reviews Cancer, 2007; 7: 169-181. http:// dx.doi.org/10.1038/nrc2088.

[17] Nabil Ismaili and Rizlane Belbaraka. Spectrum of EGFR Mutation in Lung Adenocarcinoma in Morocco. Journal of Thoracic Oncology Volume 8, Number 12, December 2013.

[18] Mok TS, Wu Y-L, Thongprasert S, et al. Gefitinib or carboplatin-paclitaxel in pulmonary adenocarcinoma. N Engl J Med 2009;361: 947957.

[19] Kosaka T, Yatabe Y, Endoh H, et al. Mutations of the epidermal growth factor receptor gene in lung cancer: biological and clinical implications. Cancer Res. 2004;64: 8919-8923.

[20] Huang SF, Liu HP, Li LH, et al. High frequency of epidermal growth factor receptor mutations with complex patterns in non-small cell lung cancers related to gefitinib responsiveness in Taiwan. Clin Cancer Res. 2004;10: 8195-8203.

[21] Shigematsu H, Gazdar AF. Somatic mutations of epidermal growth factor receptor signaling pathway in lung cancers. Int J Cancer 2006;118: 257-62.

[22] Lee $\mathrm{YJ}$, Cho BC, Jee $\mathrm{SH}$, et al. Impact of environmental tobacco smoke on the incidence of mutations in epidermal growth factor receptor gene in never-smoker patients with non-small-cell lung cancer. J Clin Oncol 2010;28:487-92.

[23] Shaw AT, Yeap BY, Mino-Kenudson M, et al. Clinical features and outcome of patients with non-smallcell lung cancer who harbor EML4-ALK. J Clin Oncol 2009; 27:4247. 